fluences; in one, the anxieties involved in vast business enterprises; in the other, the excitement of a hot political contest. These moral causes would have had no injurious effect had not the somatic conditions been unfavorable.

I come now to the most difficult part of my subject. I have to answer this important question: Why are the somatic derangements caused by the conditions referred to in some cases accompanied by the mental and nervous symptoms which belong to neurasthenia? Why do some subjects with indigestion and assimilative disorders, or with the results of dyspepsia and malaria, suffer from the derangements of the mental and nervous functions and not others? I might here take refuge behind an accepted generalization, and say that the presence or absence of the neurotic type of constitution explained the difference in the result. There is aptness in this explanation, but it is not entirely adequate. There is a mental condition of great importance, and unless we comprehend this we fail to realize all the possibilities of the nervous side of these cases. I, however, barely hint at the main points under these circumstances. Besides, I wish to avoid a too metaphysical discussion of the subject.

In the conduct of life every man who has a position to make or to maintain exerts a certain moral force to hold bimself up to his work. Some men are so happily constituted that they are quite unconscious of the effort and stand in the front, serenely confident. Others are all the time laboring; they feel it and know it; and like the soldiers of 'Thomas's corps at the battle of Chickamauga, sorely pressed, now and then look back to see whether their grim and resolute commander is still behind them with his invincible courage. Men conscious of the effort making to keep up need but little excuse to surrender themselves to their sensations. At the present time nervous prostration is much feared; its symptomatology is a common subject of discussion; and hence, if a man who is familiar with its character is arrested in his career by some of the ailments supposed to belong to it, his imagination readily supplies the rest. When a man begins the study of his bodily sensations, having a certain model in his mind, he has little difficulty iu filling out the details. All the world knows that when the attention is strongly fixed on an organ of the body functional disturbances of it ensue, and finally structural changes may be induced. No part of the body is without sensation, even in health. To perceive these sensations the attention needs to be withdrawn from external things and concentrated on the part. Thus it is when the subject of neurasthenia pursues his introspection; he becomes conscious of numerous sensations, which, because now felt for the first time, are new. Under these circumstances, also, the seat of conscious impressions becomes more acutely perceptive. Suggestion adds its quota of symptoms.

To the indefinite and multiplying nervous symptoms developing thus subjectively must be added the reflex. Headache, vertigo, tinnitus aurium, amaurosis, diplopia, hallucinations and illusions, defects of speech, paralysis, are reflex symptoms on the part of the brain; palpitation, intermittent pulse, angina pectoris, laryngismus stridulus, asthma, are amongst the reflexes of the respiratory organs and heart; neuralgia, anæsthesia, and other disorders of the sensory nerves, and local paralyses, affections of the motor nerves, included amongst the nerve reflexes, may all be dependent on reflex excitations proceeding from the stomach. deed, there is no symptom in Beard's catalogue of those belonging to neurasthenia that may not be due to merely reflex influences having their initial seat in the digestive apparatus. It follows that the term neurasthenia, or its common equivalent, nervous prostration, is either inadequate or it expresses too much, inadequate if the complex of symptoms includes the functional disturbances of all the organs affected, expresses too much if the malady is a merely nervous one.

In reply to the question: "What is meant by nervous prostration?" I respond, "A disease usually functional, situated in one or more organs, during the course of which reflex disturbances of the brain occur, and numerous subjective sensations in all parts of the body are realized by the consciousness."

I deny that neurasthenia is a primary nervous affection, or that it is a substantive disease. I hold that it is symptomatic and secondary.

This conception fixed in the mind, the treatment of neurasthenia is successful or unsuccessful according to the measure of our skill in localizing the initial disturbance, and in addressing our remedies to that as well as to the general state.

\section{THROMBOSIS AND THE CONDITIONS WHICH FAVOR ITS DEVELOPMENT.'}

BY C. H. BROCKWAY, M. D., LYNN, MASS.

SAYs a recent writer, "There is no more intricate problem awaiting solution at the hands of the clinical and pathological investigator than that of the clotting of the blood in the vessels during life." And I think I do not overstate the case by saying that no more appalling accident is brought to our notice from time to time than the sudden supervention of thrombosis or embolism, alarming and distressing the patient, - if, indeed, he escape immediate dissolution, - terrifying his friends, and causing the gravest anxiety to the physician. This event, moreover, is seldom looked for, but comes with startling suddenness in the course of diseases and morbid conditions which up to that moment had apparently been progressing favorably.

Let us look for a moment at the conditions which favor thrombosis. (1.) A stagnant or arrested circulation, as in some cases of pulmonary thrombosis, in which the clots in the arteries are probably the result of obstruction in the circulation through the lung capillaries. (2.) A mechanical obstruction around which coagula form. (3.) And most important of all (as Playfair says in writing on this subject) cases in which the coagulation is the result of some morbid state of the blood itself.

'There is, probably, no condition in which the predisposing causes of thrombosis exist in so marked a degree as in the puerperal state, and many of them are clearly exhibited even during the period of gestation. In pregnancy the blood is more watery, is deficient in red globules, and contains a larger proportion of fibrine, which must be looked upon as a waste product. So long as the excrementitious elements generated in the mother's system and that of the fotus are freely eliminated all is well, and this natural expelling of waste products goes on without disturbance while the lungs,

1 Read before the Essex South District Medical Society at Salem, December 18,1883 . 
heart, and glandular system generally are in good working order; but if for any reason the elimination of effete materials is impeded there is at once a gathering of noxious matters in the blood which promptly poisons that life-giving fluid. And yet notwithstanding the excess of fibrine and proneuess of the blood to clot during pregnancy, thrombosis is rare in this condition, the eliminative processes being ordinarily active enough to carry away the waste products; both nervous and vascular tension are high, and the glandular system works with rapidity. The marked exception as regards the kidneys, however, demands a passing remark. There are cases of sufficient frequency to come under the occasional notice of each one of us in which the kidneys fail in their proper office and permit the excrementitious elements of the urine to be retained in the blood. In such an event that fluid is loaded with a morbid and poisonous material composed not only of urea but probably of other effete materials which would be eliminated in a freer state of the abdominal circulation. In death from this form of poisoning thrombosis does not occur (so far as I can learn). If the theory of Richardion be tenable this fact may be accounted for by the presence of large quantities of carbonate of ammonia in the blood of those suffering from uræmic intoxication, thus keeping the fibrine in a state of solution.

The great majority of cases of thrombosis in lying-in women occur a variable number of days after delivery. What are the new conditions left by labor which predispose the patient more than ever to the accident of blood-clotting in the vessels. The frequency of the heart's action has been much lowered and vascular tension diminished. The drain of blood following the birth has been considerable, perhaps excessive; this causes an increased activity of absorption of good and bad material alike. During pregnancy the waste products are gotten rid of without much difficulty, the excretory organs working hard under the stimulus of a heightened vascular and nervous tension. After labor, with that tension lowered, the eliminative system is called upon to do a much greater amount of work. In fact it is in danger of being overstrained. As soon as uterine involution is well under way a great quantity of noxious material is poured into the blood. In most cases, to be sure, this is quietly expelled by the natural processes, and no untoward event occurs, but no one can for a moment doubt that the woman is in a precarious condition. This irruption of effete matter is apt to furnish that very ferment (for want of a better term) which recent writers declare to be necessary to precipitate in various localities the fibrine which was already in excess in the blood. The thrombosis thus produced is often a conservative measure, inasmuch as coagulation is apt to first take place in the uterine veins and pelvic vessels generally, thus protecting the blood as a whole from immediate infection. These venous plugs or thrombi after a time undergo a process of disintegration with a view to their ultimate removal. During this period one of the clots may become loosened from the wall of the vessel or a portion may break off from the main body of the coagulum and, entering the systemic veins, be carried along by the venous current until it reaches a vessel too small to allow of its onward progress, where it remains, plugging that vessel and, of course, producing the same symptoms as if a thrombus had originally formed at that point. This migratory plug is an embolus, showing that embolism is but an accident of thrombosis, and cannot occur but as a sequel to that event. When a clot is loosened from one of the pelvic veins and passes upward it usually ends by plugging the pulmonary artery or one of its branches, and thus causing those terrible results of pulmonary obstruction which so often end the life of the patient. It was formerly asserted by the most emineut German pathologists that this obstruction was always due to an embolus, and that primary thrombosis in the pulmonary arteries was an impossibility. This view was combated by Playfair, who produced many clinical facts to support his belief that coagulation of fibrine took place in the right side of the heart and pulmonary arteries. He reports twenty-five cases of sudden death after delivery in which accurate postmortem examination had been made, and the results are important and instructive. In seven of them there was distinct evidence of embolism, and not one of those patients died before the nineteenth day. In fifteen of them no evidence of embolism was found to account for the plugging of the pulmonary vessels; they all died within two weeks with one exception, and some in two or three days. 'The fact of death occurring so soon is in itself against the theory of embolism, as time is required to induce those degenerative changes which lead to the separation of a clot in the peripheral vessels.

Thus far I have briefly sketched the chief conditions which favor thrombosis, and have drawn illustrations from puerperal cases because the literature of the subject is comparatively rich as applied to lying-in women, and it is through these reported cases, and the commentaries that have been made upon them, that the majority of the profession has been instructed in the effects of blood-clotting in the vessels during life. ' But this affection, as you well know, is not peculiar to preguancy and the puerperal state.

It may and does occur as a complication of common diseases, and this paper is especially written to draw your attention to this fact, and to illustrate it by two cases of scarlatina occurring in my own practice, in which there was strong evidence of thrombosis of the pulmonary artery. The first patient was a boy of ten years, enjoying previous good health. He was seized with scarlatina. The eruption came out freely, the fever was high $\left(105^{\circ} \mathrm{F}\right.$. the second evening), but not unusually so, and there was nothing about the case to cause any anxiety until the sixth day. At this time the boy showed symptoms of marked exhaustion, the eruption had considerably faded, and the cervical glands, which had been moderately swollen for two or three days, suddenly grew large and painful, the pharynx was congested, and there was some pain on swallowing, but the symptoms referable to the throat were not significant. He breathed naturally, and there was nothing to draw one's attention to the chest. His appetite had failed, and he looked decidedly ill without any assignable cause other than the general blood-poisouing common to the disease. This on the sixth day. On the afternoon of the seventh I was hastily summoned, and found him suffering with horrible dyspncea and gasping for breath. 'The attack had come on suddenly, so the father said. The boy's face was rather pale. When I first arrived, only a few minutes after the attack came on, the heart was beating tumultuously ; the respiratory sounds were natural. Strong mustard poultices were applied to the front of the chest, and brandy with the aromatic spirits of ammonia was 
freely given. In half an hour the heart beat grew feebler and fluttered, the respirations became very short, and he was soon dead.

No post-mortem examination was allowed, but I think the symptoms were too significant to admit of any doubt regarding the occurrence of pulmonary obstruction, and that from a coagulum in the right heart, and extending into the pulmonary artery.

The next case was also a boy, a trifle younger, perhaps seven years of age. In him the eruption was well developed, and the fever active for a few days, when he showed marked signs of exhaustion. With the other case fresh in mind (both occurring the same year), although there was nothing in this child's condition to warrant an expectation of heart clot, I watched him carefully, and took pains to have him well nourished and the secretions kept in an active condition. at least the skin and bowels, the latter acting rather freely of themselves. The urinary secretion was fairly good; there was a trace of albumen in the urine, if $I$ remember aright, but no odema or uræmic symptoms. I gave him the carbonate of ammonia in two grain doses every hour. This was not well retained, as he vomited frequently both medicine and food. This irritability of stomach I had noticed in the boy before when treating him for various disorders. The parents considered that he always had "a weak stomach," as they termed it, and this symptom did not alarm me. He was bright, and complained of no head symptoms. This was his condition after he had been ill $\mathbf{a}$ week and a half, when his father came in haste for me one evening. I found the hoy greatly distressed for breath, a symptom which had come upon him suddenly. His dyspnœa was nearly as great as in the fatal case above narrated. His heart beat rapidly and was feeble. His respirations were of a gasping character. He was given brandy by the mouth and rectum, and mustard was applied to the chest. This relieved the violence of his dyspnoa somewhat, but yet he was evidently in a critical condition. The attempt at stimulation by the mouth was soon abandoned as he instantly rejected it. The vomiting had no apparent effect upon his breathing. He continued in this way throughout the night, being worse at times, but relieved by the stimulant, and especially by having him breathe an atmosphere surcharged with the vapor of water, as is customary in cases of croup. The next day he was more comfortable, though still much distressed. He was kept quiet, sinapisms applied to the chest, and brandy given at intervals when his symptoms demanded it. He gradually recovered. It may be doubted whether this was a case of pulmonary obstruction, but the symptoms were well marked, and to me unaccountable on any other hypothesis.

Playfair records a number of cases of recovery with symptoms the same as above recorded occurring in women after labor. As he says, "if the obstruction be only partial and sufficient blood pass to keep the patient alive," recovery is surely not impossible.

Cases of sudden death from thrombosis occur now and then in diphtheria. Flint says that he lost one patient in acute rheumatisn from the sudden occurrence of a coagulum in the right ventricle, passing into and obstructing the pulmonary artery. Tamner believes that the sudden death of many patients with croup is due oftener to thrombi than to asphyxia.

One word as to treatment. In the way of preventive medicine $I$ know of nothing unless we give as a routine practice the carbonate of ammonia in large doses in all cases whenever we have reason to think the occurrence of heart clot possible. But this hardly seems practicable, and its efficacy is doubtful. The eliminative organs should be kept in active condition by every means in our power, and I have thought that the sulphite of soda might be freely used with benefit in all septic conditions of the system.

\section{Hoguital Bractice and Clinital $\mathfrak{A H e m o r a n d a . ~}$}

\section{TWO CASES OF UTERINE POLYPUS.1}

\author{
BY Francis MiNOT, M. D.
}

The first patient was a married woman, forty-nine years old, who had never been pregnant. General health good till about three years ago, when the menstruation became frequent and profuse. For the past three months the hæmorrhage had been continuous. She entered the Massachusetts General Hospital in a very anæmic and debilitated condition. The uterus could be felt above the pubes, and was not apparently enlarged. On vaginal examination the cervix was found to be very large, spherical in shape, with an opening in the presenting part into which the finger could penetrate with some difficulty. A smooth, hard mass was felt within it, not adherent to the walls of the cervix. On account of want of space the pedicle of the tumor could not be felt. A loop of twisted wires was passed over the tumor and tightened by an écraseur until the pedicle was cut through. The tumor was then removed without much difficulty, the os being incised in two directions to permit its exit. The vagina and cervix were carefully sponged out with a solution of carbolic acid, and the vulva was covered with salicylated cotton. Scarcely a drop of blood was lost. The perinæum was frequently bathed with carbolic acid solution. The operation was done March 16th. The next day there were no symptoms, but on the 18th the temperature rose to $100^{\circ} \mathrm{F}$., and carbolized vaginal douches were ordered. On the 19 th there was a chill ; on the 20 th, vomiting. The temperature continued to rise, the abdomen became tympanitic and tender, and she died March 22d at midnight. The tumor was an ordinary fibroid of the size and shape of a lemon. In addition to the carbolic douches eight grains of quinine were given every four hours, besides morphia, etc. It was found, after the patient's death, that there was a case of erysipelas in an adjoining room, and, notwithstanding the precautions taken, there can be no doubt that the fatal result was owing to septicæmia originating by contagion.

The second case was that of a married woman, who entered the hospital at about the same time as the above, and whose history was almost identical with hers. The tumor was wholly extruded from the uterus, and occupied the vagina. It was somewhat smaller than the first, and was nearly spherical. It was drawn down with hooks, and separated from the stalk before the latter could be severed with scissors. The patient was carefully isolated, and every precaution was taken to prevent infection. 'There was no untoward symptom, and she left the hospital in a few days, well.

1 Read before the Obstetrical Society of Boston, March 10, 1882. 